yet available to the public, and when they are produced they will cost $£ 30-£ 100$ each. Both the German Post Office and the Broadcasting Company are, however, eager to provide the public with means whereby they can form an opinion of the entertainment value of the new service. Accordingly, the Post Office has opened a televiewing room in Berlin where reception is demonstrated every morning. Also, in co-operation with the German Listeners' Association, four similar rooms have been opened in other parts of the city where the public can witness the reception of the evening programmes. No charge is made for admittance, although to prevent undue crowding, tickets are issued and the attendance of each person is limited to half an hour. Thus during an evening programme of one hour and a half, three groups of 40-50 persons can have a demonstration at each centre. It is intended to extend these free facilities so that television, even in its present stage, will not be limited to the small group of persons who are financially in a position to buy apparatus.

\section{Visibility Distance of Pedestrians}

Tests were carried out last year by the Massachusetts Highway Accident Survey with the object of finding out by actual experiment the distance at which the driver of a motor vehicle can see a pedestrian who is walking along the side of a highway at night. The tests are analysed and discussed in a paper by P. Moon and R. C. Warring (J. Franklin Inst., March). The principal conclusions arrived at are that the visibility of a pedestrian walking along a highway at night is increased by roughly 50 per cent by showing a small area of white such as a handkerchief. Three reflector buttons, such as those employed in reflecting type highway signs, worn with dark clothing increase the visibility distance by 100 per cent, the same as that produced by a large area of white. It was found that the maximum safe speed at night was approximately 30 m.p.h., but if there was no glare from passing cars it was 40 m.p.h. These speeds are the optimum values. The time lag of the driver seems to vary between 0.5 sec. and 1 sec. even when the surprise element is lacking. On unlighted roads the type of the pavement and the speed of the car have little effect on the visibility distance. The tests show that it is advisable not to have the candle-power of the headlamps less than 32 . Experience shows that depressing the headlamp beams so as to diminish glare reduces the visibility distance. Another important conclusion is that highway lighting does not increase visibility distance unless the average luminosity of the pavement is above the chromatic threshold, which is generally taken to be of the order 0.05 lumen per square foot.

\section{The Camionale Genoa-Serravalle for Lorry Traffic}

THe handling of the large import and export traffic of Genoa is a problem that has been studied by many Italian Governments. A satisfactory solution has now been found. A full description of the first section of the new motor road for heavy lorries (camions) called the Camionale is published in
Engineering of June 28. The electrification of the railway from Genoa to Roneo over the Giovi mountain range in 1916 increased the capacity of the line more than four times. When this proved insufficient, a more direct electric railway was projected between Genoa and Arquata, necessitating the construction of a tunnel ten miles long through the Giovi mountains. The development of motor road transport and the success of the autostrada connecting Milan and Como, Naples and Pompeii, etc., created a new situation. The autostrada are characterised by the absence of practically all crossings and have minimum gradients and curves of long radius. No pedestrians are allowed on them. The new motor road, or Camionale, will ultimately join Genoa with Milan and Turin, and the projected electric railway has been abandoned. The Camionale starts from a large square near the Port of Genoa and traverses the Promontorio and Belvedere Hills by means of two long tunnels. After passing through many further tunnels, the road passes over the Montanesi torrent by means of a picturesque viaduct. In the Littorio tunnel, 2,926 ft. in length, the road reaches its highest altitude, 1,255 ft. above sea-level, at a distance of 13 miles from the terminal square at Genoa. The terminus at Serravalle Scrivia is 31 miles distant from Genoa. The geological conditions made the construction of the Camionale very difficult. The width of the road is 10 metres ( $32 \mathrm{ft} .10 \mathrm{in}$.). The total cost of construction of the Camionale is about $3 \frac{1}{2}$ million sterling at the present rate of exchange.

\section{Australian Institute of Agricultural Science}

IN January 1935 the Australian Institute of Agricultural Science was inaugurated, with Prof. A. E. V. Richardson, of the Waite Institute, as its first president. The presidential message states that "the major work of the Institute will be the development of an esprit de corps among the members of the profession throughout the Commonwealth, and in assisting in the formation of a public opinion which will insist that the agricultural and pastoral resources of Australia should be developed by the best known methods and utilised to the best advantage attain. able". The constitution provides for periodical meetings of the Institute and its local branches, and also for the publication of a journal of which the first number has now appeared (vol. 1, No. 1, March 1935). It is intended that this journal shall be devoted to the publication of leading articles, reviews of present states of knowledge, research papers, technical notes and other items of a professional and general nature. The current number gives some indication of the wide field of interests it is proposed to cover. Contributed articles deal with agricultural science in the Soviet Union, and with rural relief and agricultural extension. The economic side is catered for by an article dealing with commerce and agricultural research and also by abstracts of a discussion on "Plant Quarantine" at the Melbourne meeting of the Australian and New Zealand Association for the Advancement of Science. The technical notes deal with various problems in agricultural plant physiology, entomology and pathology, while a column of 